ISSN: 0213-2079 - ISSN electrónico: 2386-3889

DOI: http://dx.doi.org/10.14201/shhmo201537269290

\title{
CONSUMOS Y APARIENCIAS EXTERNAS DE LAS FAMILIAS DE LA BURGUESÍA LEONESA (1700-1850) ${ }^{1}$
}

\section{Consumption and External Appearances of Bourgeois Families in León (1700-1850)}

\author{
Juan Manuel BARTOLOMÉ BARTOLOMÉ \\ Universidad de León \\ Correo-e: jmbarb@unileon.es
}

RESUMEN: Tomando como referencia las familias de la burguesía de los negocios y de los funcionarios y empleados de la administración de la provincia de León, hemos profundizado en la historia del consumo centrándonos en las apariencias externas -vestimenta y adornos de valor, objetos y alhajas de oro y plata, etc.-, fijándonos en los contrastes en relación con factores diversos: niveles patrimoniales, profesión, género, residencia-ciudad o villas-, etc. De este modo, se observan pautas de consumo diferenciadas entre las familias burguesas señaladas. Así, son las conectadas con las profesiones liberales y de la administración de la ciudad las pioneras en la llegada de las nuevas modas, tanto en la ropa destinada a vestir el cuerpo como las joyas y alhajas de uso personal. En cambio, la burguesía comercial asimilará, consumo vicario, las modas con mayor retraso, pero su consumo será más intenso, sobre todo a partir los años treinta del siglo XIX.

Palabras clave: Familias burguesas; provincia León; Consumo; Modas; Vestimenta externa; joyas personales.

1. Este trabajo se inscribe en el proyecto de investigación del Ministerio de Ciencia e Innovación: Familia, identidad social, transmisión hereditaria y cultura material. Patrimonios, consumos y apariencias en la Castilla interior, 1600-1850 (HAR2010-21325-CO5-05). 


\begin{abstract}
Having as reference the bourgeois families, civil servants and employees of Provincial Administration of León, we have studied the consumption history focusing on external appearances such as clothes, jewelry, objects made of silver or gold, etc., according to the different levels of wealth, professions, places where they lived (cities or villages), gender... We have observed several tendencies of consumption among the families above mentioned. Thus liberal professions and employees of administration, were quickly interested in the new trends, as much jewelry as clothes. In contrast, commercial families will imitate these trends much later but in a more intensive way, over all from thirties of the nineteenth century.
\end{abstract}

Key words: Bourgeois families; province of León; consumption; trends; external clothes; personal jewelry.

En los momentos actuales en la historia que denominamos del consumo ${ }^{2}$ interesa tanto lo que se consume y las cantidades, como quién y dónde, ya que a través de estos comportamientos se van forjando la construcción de identidades de status y clase social ${ }^{3}$.

Indudablemente, la llegada del sentido moderno de la privacidad y la individualidad generó una nueva concepción de los espacios del interior doméstico, que trajo consigo nuevos estímulos en la demanda de productos. A su vez también las formas de sociabilidad burguesa, con la extensión de los paseos y la asistencia a espectáculos, animaron a la exposición de las nuevas pautas de consumo y lógicamente a la emulación de las novedades. De este modo, el gran interrogante que se nos plantea es averiguar si existían demandas diferenciadas de acuerdo con las categorías socioprofesionales. De ahí, la relevancia del estudio de los consumos

2. Dados los límites del trabajo no consideramos conveniente realizar una relación pormenorizada de los estudios sobre el consumo desarrollados desde los trabajos pioneros de Giovanni Levi o Paolo Malanima, a los que se unieron los planteamientos novedosos en economía de Neil MacKendrick o Jean de Vries, («La revolución industriosa»), o sociales (D. Roche para Fancia, R. Sarti y R. Ago para Italia, N. L. Madureira para Portugal), etc., únicamente queremos remarcar que en España desde sus inicios los estudios han derivado también hacia una tendencia más social y cultural, tal como se puede apreciar desde los primeros trabajos surgidos, hace más de diez años, bajo la dirección del proyecto de Bartolomé Yun Casalilla, hasta las publicaciones más actuales del grupo de investigación coordinado por Máximo García Fernández, como la de Dos Guimaraes Sá, I. y García Fernández, M.: (dirs.): Portas Adentro, comer, vestir, habitar (ss. XVI-XIX). Coimbra, Valladolid, 2010. García Fernández, M.: (dir.): Cultura material y vida cotidiana moderna: escenarios. Madrid, 2013. Bartolomé Bartolomé. J. M. y García Fernández, M. (dirs.): Apariencias contrastadas: Contraste de Apariencias. Cultura material y consumos de Antiguo Régimen. León, 2012.

3. Yun Casalilla, B.: Prólogo de Comprar, vender y consumir. Nuevas aportaciones a la historia del consumo en la España moderna. Muñoz Navarro, D. (ed.): Valencia, 2011, p. 11. 
conectados con las apariencias externas, es decir, tanto de las prendas para vestir el cuerpo como también con los objetos o alhajas decorativos.

Teniendo en cuenta que son las familias burguesas las que adoptan y asimilan primero a nivel cronológico las novedades del consumo, tal como conocemos por la historiografía ${ }^{4}$, el análisis se realizará sobre las familias de comerciantes, comerciantes-financieros, y de la burguesía administrativa y de profesiones liberales de la provincia de León, en el marco cronológico de 1700-18505.

Por ello, tomando como base la información que nos proporcionan las fuentes literarias y fundamentalmente los protocolos notariales ${ }^{6}$, nos hemos planteado

4. Estudios de Roche, D.: La Culture des apparences. Une historie du vetemement, XVII-XVIII siècles, París, 1989; Historire des choses banales. Naissance de la consommation XVII-XIX siècle. París, 1997. Madureira, N. L.: Cidade: Espaço e Quotidian. Lisboa, 1992. García Fernández, M. (dir.): Cultura material y vida cotidiana..., p. 9.

5. El criterio empleado es el funcional, considerando a los individuos que ejerzan profesiones comerciales y financieras, o ambas de forma conjunta, y funciones administrativas y liberales, adquiridas básicamente mediante el estudio y no con una formación empírica. TorRes Sánchez, R.: «El hogar del burgués», en La Burguesía Española en la Edad Moderna, tomo I. Valladolid, 1996, pp. 258-259. En la administrativa, hemos agrupado a las personas que desempeñan cargos que dependen de la administración central o provincial: contadores de rentas reales, procuradores del número, administradores del excusado y casa diezmera, abogado de los Reales Consejos, etc. Y en la de profesiones liberales a médicos titulares, maestros arquitectos, abogados, escribanos, notarios, etc. Es decir, a los que poseían, en general, un título que les facultaba para el ejercicio de una profesión de carácter liberal, incluidos los más numerosos juristas, graduados en leyes, pero que a diferencia de los anteriores no estaban empleados en la administración del estado o de los municipios. Molas Ribalta, P.: La Burguesía mercantil en la España del Antiguo Régimen. Salamanca, 1985, p. 23.

6. De las escrituras de protocolos notariales hay que precisar que en los testamentos se efectúan mandas a parientes o criados, sobre todo criadas, de ropas y alhajas, pero con el inconveniente de que en general no se concreta su valor y a veces tampoco se especifica el tipo de piezas, acudiendo a la fórmula genérica: «toda la ropa exterior que tengo...». En cuanto a las escrituras de dote son muy escasas en las familias analizadas y solo en los testamentos y sobre todo en las cuentas de testamentaría se hacen referencias a las cantidades prometidas, generalmente en dinero y joyas, a los futuros esposos, pero de nuevo con la particularidad de que en general aparecen las cantidades globales y no la relación pormenorizada de las joyas y alhajas. Por ello, consideramos que la mejor fuente disponible, a pesar de sus limitaciones, son los inventarios de bienes y las cuentas de testamentaría, o partijas de bienes, que también incluyen un inventario postmortem.

En el trabajo de Eiras Roel, A.: «Tipología documental de los protocolos gallegos», en La Historia social de Galicia en sus fuentes de protocolos. Santiago de Compostela, pp. 28-29, existe una interesante información bibliográfica sobre esta cuestión. Después de haber vaciado todos los protocolos notariales de la ciudad de León y la mayor parte de las villas a la que se hace referencia de la provincia durante el periodo estudiado, disponemos de una muestra de inventarios de 19 familias de la burguesía comercial y financiera (diez de la ciudad de León y nueve de las villas de Ponferrada, Astorga, etc.), y 17 de las de la burguesía administrativa y de profesiones liberales (quince de la ciudad de León y dos de la villa de Ponferrada). Teniendo en cuenta que en cada familia reconstruida, sobre todo de los comerciantes, hay más de un inventario, el resultado final es de 32 inventarios para los comerciantes y financieros y 22 para los de profesiones administrativas y liberales. También hay que precisar que para este tipo de estudio solo hemos podido utilizar los inventarios donde se recogen 
como gran objetivo estudiar el consumo de las apariencias externas, es decir, de la vestimenta y adornos personales, fijándonos en los contrastes entre las diversas familias burguesas en relación con su profesión o actividad y de acuerdo con su ubicación o lugar de residencia, la capital, o villas de menor entidad: Ponferrada, Astorga, etc. Además, no debemos perder nunca de vista la cuestión de género ${ }^{7}$ y la cronología, ya que además de profesión y residencia lo que realmente interesa es cuándo llegan las novedades. Finalmente, tampoco habrá que descuidar los patrimonios familiares y la relación de sus riquezas con la propensión mayor o menor al consumo de las novedades conectadas con las apariencias externas.

\section{LAS FAMILIAS OBJETO DE ESTUDIO: SUS PATRIMONIOS Y ESTRUCTURAS}

Las medias patrimoniales de los comerciantes de la ciudad de León, en el siglo XVIII y primera mitad del XIX ${ }^{8}$, se sitúan en 504.091 reales, los cuales una vez descontadas las deudas, el pasivo (que supone tan solo un $8 \%$ ), quedan líquidos 463.890 reales de media ${ }^{9}$. Los de los comerciantes de las villas de Astorga, La Bañeza y Ponferrada son más inferiores ${ }^{10}$. Los más elevados de la capital están todavía muy

los bienes objeto de análisis y su tasación. Quizás las mandas previas de los mismos, difíciles de rastrear tal como ya se ha señalado en la documentación, ensombrezcan el panorama de la muestra. No obstante, en la ciudad de León a mediados del siglo xviII, 1751, entre sus aproximadamente 6.000 habitantes el número de personas dedicadas a este tipo de actividades no era muy elevado: 106 escribanos y notarios y 107 de comerciantes y tenderos. En las villas de la provincia como es lógico su número es menor: 52 comerciantes y arrieros en Ponferrada para mediados del siglo xviII y 53 de profesiones administrativas y liberales. En Astorga 10 tenderos y regatones y 24 abogados, notarios y escribanos. Familias que por otro lado no experimentarán grandes cambios en cuanto a su número en el periodo estudiado. Bartolomé Bartolomé, J. M.: Vino y viticultores en El Bierzo. Sociedad y estructuras económicas durante el siglo XVIII. León, 1996, pp. 162-163. Rubio Pérez, L.: León, 1751. Según las Respuestas Generales del Catastro de Ensenada. Madrid, 1993; Astorga. Un enclave señorial en los siglos XVII y XVIII. León, 1990, pp. 72 y 73.

7. Aunque la demanda masculina y femenina generase modelos finales parecidos (majismo). García Fernández, M.: Prefacio Cultura e identidades..., p. 9.

8. Según los inventarios postmortem con los bienes tasados y las partijas de bienes.

9. En Albacete no es posible obtener medias de la riqueza, pero todo parece indicar que se tratarían de valores muy similares, ya que la tasación de la fortuna diez años antes de morir de uno de los comerciantes más ricos, Ignacio Suárez, era de 1.500 .000 reales. Sin embargo en la siguiente generación todos sus descendientes -o al menos casi todos- experimentaron un descenso social muy importante. Gómez Carrasco, C. J.: Familia y capital comercial en la Castilla meridional. La comunidad mercantil en Albacete (1700-1835). Madrid, 2009. p. 128.

10. En la burguesía maragata solo tres casos de un total de dieciséis superan dicha cantidad. La burguesía de la provincia, bañezana, astorgana y berciana, del siglo xviII está también muy por debajo, en torno a unos 39.000 reales. Y solo en El Bierzo, en la primera mitad del siglo xIx se aproximan a las medias señaladas. Rubio Pérez, L.: La burguesía maragata. Dimensión social, comercio y capital en la corona de Castilla durante la Edad Moderna. León, 1995. Bartolomé Bartolomé, J. M.: Vino y viticultores en El Bierzo. Sociedad y estructuras económicas durante el siglo XVIII. León, 1996. La begemonía de una nueva burguesía en El Bierzo (1800-1850). León, 2000. El tránsito al crecimiento 
alejados de la burguesía interior comercial vitoriana o extremeña ${ }^{11}$ y a años luz de la de los puertos como la valenciana o gaditana ${ }^{12}$. Incluso, la burguesía comercial financiera de la citada ciudad del interior peninsular, durante la cronología ya señalada, ofrece unos líquidos patrimoniales, 893.883 reales, muy por debajo de la burguesía gaditana y de los comerciantes banqueros extremeños ${ }^{13}$. No obstante, son patrimonios solventes en relación con otros grupos sociales provinciales ${ }^{14}$.

El estudio más pormenorizado de la estructura interna de esta riqueza patrimonial, nos señala que en la burguesía comercial son lógicamente los bienes mobiliarios los que tienen un mayor peso ${ }^{15}$, lo cual está en conexión directa con la relevancia dentro de los mismos de los conceptos o partidas más vinculadas a la actividad mercantil. De este modo, en los comerciantes de la capital el $92,7 \%$ de los bienes tasados en la riqueza mobiliaria son los relacionados con el negocio y dentro de los mismos van a ser las deudas a favor del comercio las que se sitúen a la cabeza, un $37 \%$ de la riqueza mobiliaria y un $23,6 \%$ del activo patrimonial, seguidos muy de cerca por los géneros de comercio en stock, el $35,7 \%$ y el $22,7 \%$ respectivamente, y finalmente, a una mayor distancia, el dinero líquido, en efectivo, disponible, un $18,9 \%$ y un $12,1 \%$ respectivamente. Por lo tanto, se reproduce el mismo esquema que en la burguesía interior vitoriana o navarra e incluso de la periférica de Valencia, pero con la particularidad de que en nuestra burguesía tienen menor importancia los créditos o deudas a favor y en cambio es más alta la

económico moderno en León. Condiciones de vida y pautas de consumo en La Bañeza y Astorga. León, 2004, pp. 35-38.

11. En Vitoria el porcentaje de casas mercantiles con niveles líquidos por debajo de los 500.000 reales es del 58,3\%, Angulo Morales, A.: Del éxito en los negocios al fracaso del consulado: la formación de la burguesía mercantil en Vitoria (1670-1840). Bilbao, 2000, pp. 297. En Extremadura de cinco casos solo uno está por debajo con un líquido de 189.974 reales. Melón Jiménez, M. A.: Los orígenes del capital comercial y financiero en Extremadura. Compañias de comercios, comerciantes y banqueros de Cáceres (1773-1836). Badajoz, 1992, pp. 119-120.

12. En Valencia por debajo de las 35.000 libras (que vendrían a equivaler aproximadamente a 500.000 reales) se sitúan el 37,73\% de los inventarios analizados. Franch Benavent, R.: El capital comercial valenciano en el siglo XVIII. Valencia, 1989, p. 38. En Cádiz, con una orientación más financiera que comercial, las estimaciones rondaban entre 3.570 .000 y unos 14.280 .000 reales. García Baquero. A.: Cádiz y el Atlántico (1717-1778). Sevilla, 1976, pp. 510-511.

13. Melón Jiménez, M. A.: Los orígenes del capital comercial..., p. 139.

14. Aunque es difícil averiguar la cuantía de los patrimonios de la nobleza leonesa, ya que sus bienes se hallaban en gran medida vinculados, sí que podemos señalar que los bienes libres de los regidores leoneses en el siglo XviII se situaban entre un mínimo de 29.696 reales y un máximo de 134.189 reales. Y solo el vizconde Quintanilla en 1817, don Joaquín Flórez Osorio, tendrá 449.818 reales. Como es lógico, los niveles patrimoniales de la mayoría de la población, artesanos y sobre todo campesinos, estarán muy por debajo: entre los 8.251 reales de los campesinos bercianos y los 21.218 reales de los de la Vega Baja del Esla. Bartolomé Bartolomé, J. M.: Vino y viticultores...; Pérez García, J. M.: Un modelo social leonés en crecimiento. La Vega Baja del Esla entre 1700-1850. León, 1989.

15. El $74,5 \%$ en la ciudad de León y el $96,1 \%$ en la villa de La Bañeza en el siglo xviII. 
tasación de los artículos que se encuentran depositados en los respectivos almacenes o lonjas esperando su salida al mercado ${ }^{16}$.

También la burguesía comercial mostrará un gran interés hacia la propiedad en viviendas y dependencias complementarias ${ }^{17}$, las cuales se consideraban, además, fundamentales para poder asentar y desarrollar sus negocios: casas y lonjas. También, al igual que el resto de la burguesía española ${ }^{18}$, se interesarán por adquirir tierras de labor ${ }^{19}$, lo que nos demuestra la inclinación de estas familias burguesas hacia unas inversiones consideradas muy atractiva no solo por su grado de seguridad y su carácter rentista, sino también por su fuerte sentido social como espejo del éxito en los negocios ${ }^{20}$. Además, con la particularidad de que en terceras generaciones y para la primera mitad del siglo xIx la tendencia hacia la posesión de tierras de labor es aún más fuerte, beneficiándose de la exclaustración de los mismos en la desamortización del Trienio y sobre todo de Mendizabal ${ }^{21}$.

Las familias de la burguesía administrativa y de profesiones liberales que residen en la capital ofrecen unos niveles medios patrimoniales, una vez descontado el pasivo, las deudas que suponen un $5,4 \%$ y un $7,7 \%$ en la burguesía administrativa

16. Los «créditos a favor de la casa» eran la partida de mayor relevancia de las burguesías mencionadas, llegando a suponer en Valencia en el $76 \%$ de los casos por encima del $25 \%$ del activo y en Vitoria entre un $30 \%$ y un $70 \%$ del valor de sus activos. Angulo Morales, A.: Del éxito en los negocios..., p. 308. Franch Benavent, R.: El capital comercial..., pp. 250-251. Azcona Guerra, A. M. ${ }^{\text {: }}$ Comercio y comerciantes en la Navarra del siglo XVIII. Navarra, 1996, p. 307.

17. Un $17,1 \%$ de la riqueza patrimonial en la ciudad de León y un espectacular $62,6 \%$ en la villa de Astorga. BARTOlomé Bartolomé, J. M.: Familias de comerciantes y financieros en la ciudad de León (1700-1850). León, 2009. El tránsito al crecimiento económico..., pp. 35-38.

18. Al igual que sucede en Albacete donde fue una tónica general, en tanto en cuanto las familias de comerciantes fueron acumulando capital líquido. Gómez Carrasco, C. J.: Familia y capital comercial..., pp. 107-120. Según Marcos Martín, A., esta actitud es constante a lo largo del Antiguo Régimen y no se circunscribe únicamente a las épocas de dificultades, «Historia y desarrollo: el mito historiográfico de la burguesía», en La Burguesía Española en la Edad Moderna. Valladolid, 1996, pp. 21-22.

19. Las cuales suponen el $8 \%$ de la riqueza patrimonial en los comerciantes capitalinos y un $3,8 \%$ en los de la villa de La Bañeza.

20. Angulo Morales, A.: Del éxito en los negocios..., p. 332.

21. Es lo mismo que se aprecia en la burguesía de Navarra. Azcona Guerra, A. M.a.: Comercio y comerciantes..., p. 547. En el caso de León nos puede servir como ejemplo el de la familia Fernández-Chicarro, ya que en su tercera generación, por lo años cuarenta del siglo xIx, don José y su esposa con un activo patrimonial líquido próximo al millón de reales, 923.191 reales, tienen bienes inmobiliarios que suponen un poco más de la mitad del valor patrimonial, un 57,4\%, y de ellos el $22,9 \%$ son tierras, viñas, huertas y particularmente prados, algunas localizadas en pueblos gallegos, lo cual puede ser debido también al pago hipotecario de deudas contraídas por el comercio. Archivo Histórico Provincial de León [en adelante AHPL], Félix de las Vallinas, Caja 1137. Además, también conocemos por las legítimas que la mayoría de estas tierras son compradas por el nuevo matrimonio y no heredadas. Id., Juan de Dios Fernández, Caja 955. 
y de profesiones liberales respectivamente ${ }^{22}$, más bajos, 216.669 reales en la administrativa y 116.489 reales en la de profesiones liberales. De todas formas, serán más altos que los de las familias de las mismas profesiones de la zona rural leonesa de El Bierzo, donde no llegarán a 18.000 reales para el siglo XviII ${ }^{23}$.

En la estructura de su riqueza, en primer lugar, sorprende la escasa importancia que tiene la tasación de los oficios profesionales, ya que su valoración es nula en la burguesía administrativa y en la de profesiones liberales solo representa un 1,5\% de la total de la riqueza patrimonial ${ }^{24}$. Y en segundo lugar, se aprecian diferencias muy claras entre las dos burguesías, ya que mientras la burguesía administrativa mantiene un esquema similar a la comercial de la ciudad de León: fuerte predominio de los bienes mobiliarios, con un $73, \%$, seguidos de las viviendas y dependencias complementarias con un $13,9 \%$ y de las tierras de labor con un $11,7 \%{ }^{25}$; sin embargo, en la burguesía de profesiones liberales constituyen la mayor partida las viviendas y dependencia complementarias con un 35,7\% y los bienes mobiliarios descienden a un segundo lugar con un $33,8 \%$, seguidos por las tierras de labor con un $28,1 \%{ }^{26}$.

Si pasamos a un estudio más pormenorizado, en la burguesía administrativa, tal como se ha mencionado, son los bienes mobiliarios, con un $73,9 \%$, los que conforman la partida más relevante de sus patrimonios ${ }^{27}$. Las viviendas y dependencias complementarias ocupan el segundo lugar con un $13,9 \%{ }^{28}$. Entre las mismas sobresalen las casas propias destinadas a lugares de residencia o para arrendarlas, únicamente en un caso tiene en propiedad nueve casas, ${ }^{29}$ y solo de

22. Pasivo o deudas que no son muy elevadas, ya que las de la burguesía comercial y financiera eran del 8\%. Bartolomé Bartolomé, J. M.: Familias de comerciantes y financieros... op. cit.

23. Bartolomé Bartolomé, J. M.: Vino y Viticultores en El Bierzo..., p. 211

24. Quizás sea debido a que la mayoría de los oficios no son hereditarios y por ello no se efectúa una valoración del mismo a la hora de realizar el inventario general de bienes.

25. Esta predilección por las inversiones en tierras también se aprecia en la burguesía de Santiago de Compostela, Barreiro Ballón, B.: «Las clases urbanas de Santiago en el siglo xviII: definición de un estilo de vida y de pensamiento» en La historia Social de Galicia en sus fuentes de protocolos. Santiago de Compostela, 1980, pp. 466-467.

26. Este interés por la posesión de casas, tierras de labor, explotadas mediante el arrendamiento, y las actividades crediticias también se aprecian en el profesorado vallisoletano de la segunda mitad del siglo xix. Dávila Corona, R. M.: «La cultura doméstica del profesorado vallisoletano en la segunda mitad del siglo XIX», en Las Universidades Hispánicas. De la monarquía de los Austrias al centralismo liberal. Universidad de Salamanca, pp. 128-130.

27. En la burguesía comercial eran el 74,5\%, lo cual resultaba más lógico debido a los conceptos relacionados con sus negocios: deudas a favor, géneros almacenados, dinero en efectivo, etc., BARTOlomé BARTOlomé, J. M.: Familias de comerciantes y financieros... op. cit.

28. Valor inferior al de la burguesía comercial, con un $17,1 \%$, debido a la importancia que tenían como espacios destinados a sus negocios. Ibidem.

29. Se trata del abogado de los Reales Consejos, don Manuel García Brizuela, en cuyo inventario se registran y tasan nueve casas valoradas en 104.086 reales, las cuales, exceptuando una donde vive un hijo, las tiene arrendadas. AHPL, Pedro Hevia Lorenzana, Caja 749. 
forma más testimonial poseerán molinos ${ }^{30}$. Es relevante también la propiedad de tierras situadas en el terrazgo de los pueblos próximos a la ciudad ${ }^{31}$, entre las mismas sobresalen las tierras de cereal de secano, pero también mostrarán una fuerte predilección por las tierras de mayor valor, en concreto por las huertas y prados, los cuales constituyen un porcentaje superior al 42,9\% de la tasación. En cambio, el viñedo aparecerá de forma muy minoritaria con tan solo un 3,8\% de la valoración de las tierras. Conectado con la ausencia de explotación directa de la tierra nos encontramos con la propiedad de una cabaña ganadera muy reducida, casi simbólica, donde lo que más abundan son los animales destinados al uso personal: mulas, caballos, etc, frente al bovino y ovino ${ }^{32}$.

En la burguesía de profesiones liberales, son las casas las que tienen la mayor valoración. Ello es debido, a la alta propiedad de estos inmuebles urbanos, tanto por parte de médicos titulares, como de escribanos y sobre todo de maestros arquitectos, lo cual estaría conectado con la profesión desarrollada ${ }^{33}$. También se inclinaran hacia la posesión de tierras de labor, sobre todo de cereal de secano ${ }^{34}$, para cederlas en arrendamiento ${ }^{35}$.

\section{VESTIR EL CUERPO: LA LLEGADA DE NOVEDADES}

En las familias de la burguesía comercial y financiera que reside en la capital, las prendas del ropero masculino a lo largo del siglo XVIII seguirán siendo en general las tradicionales. Así, predominarán los calzones, las casacas, las chupas, las camisas, las capas, las calcetas, etc. Tampoco faltarán, aunque su presencia es más

30. En concreto solo se relacionan cuatro, y tres de ellos son de un solo propietario, don Roque de Diego Pinillos, tasados en 73.275 reales. Id., José Casimiro Quijano, caja 1185.

31. Con un $11,7 \%$ es superior a la de la burguesía comercial con un $8 \%$, Bartolomé BartoLOMÉ, J. M.: Familias de comerciantes y financieros..., op. cit.

32. Solo en el inventario de don Francisco Díez Campomanes, procurador del número, realizado en 1806, figura un rebaño cabrío y dos vacas y un buey que son de su propiedad y no parece estén dados en aparecería. AHPL, Domingo Castañón Rodríguez, caja 910.

33. Es lo que sucede con don Fernando Sánchez Pertejo, arquitecto, en cuyo inventario, en 1.840, figuran un total de trece casas tasadas en la elevada cantidad de 184.160 reales, las cuales, aunque no se señala a quién ni los años de su compra, seguro fueron adquiridas en las desamortizaciones respectivas, sobre todo la del trienio liberal, y las explota mediante el sistema de arrendamientos. Idem, Félix de las Vallinas, Caja 1135.

34. Las huertas y prados descienden al $20,8 \%$ de la tasación de las tierras.

35. Los casos más destacados son los del arquitecto ya citado, don Fernando Sánchez Pertejo, que posee tierras valoradas en 111.034 reales, y sobre todo el del procurador don José González Luna, el cual fallece en $1749 \mathrm{y}$ en su inventario postmortem se tasan las tierras, cereal, huertas, prados, en 125.589 reales, cuando su líquido patrimonial fue de 251.079 reales, brillando por su ausencia en el mismo inventario no solo los útiles de labranza, sino también cualquier tipo de cabaña ganadera. AHPL, Domingo Castañón Rodríguez, caja 903. 
testimonial, los codiciados jubones y los fracs con sus correspondientes chupas ${ }^{36}$. Prendas de vestir el exterior del cuerpo elaboradas con las fibras ya conocidas tradicionales: las más finas como el lino para las camisas y la más resistente, las de lana, para las restantes, y de colores poco vivos: sobre todo negros y algún azul. Las prendas más íntimas de la ropa interior se centrarán en los calzoncillos tanto de adulto como de niño ${ }^{37}$.

CuAdro 1. Las nuevas prendas en la vestimenta personal de la burguesía comercial y financiera. Ciudad de León (1750-1850). (Piezas y porcentajes según el stock de bienes totales inventariados)

\begin{tabular}{|l|c|c|c|c|c|c|c|c|}
\hline & \multicolumn{2}{|c|}{$1750-1799$} & \multicolumn{2}{c|}{$1800-1824$} & \multicolumn{2}{c|}{$1825-1850$} & \multicolumn{2}{c|}{ TOTALES } \\
\hline PRENDAS MASCULINAS & $\mathrm{N}^{\circ}$ & $\%$ & $\mathrm{~N}^{\circ}$ & $\%$ & $\mathrm{~N}^{\circ}$ & $\%$ & $\mathrm{~N}^{\circ}$ & $\%$ \\
\hline Chalecos & 5 & 8,6 & 13 & 22,4 & 40 & 69 & 58 & 100 \\
\hline Chaquetas & - & - & 1 & 8,3 & 11 & 91,7 & 12 & 100 \\
\hline Pantalones & - & - & - & - & 14 & 100 & 14 & 100 \\
\hline Sombreros & - & - & - & - & 8 & 100 & 8 & 100 \\
\hline Guantes & - & - & - & - & 4 & 100 & 4 & 100 \\
\hline PRENDAS FEMENINAS & & & & & & & & \\
\hline Vestidos & - & - & - & - & 22 & 100 & 22 & 100 \\
\hline Pañuelos & 16 & 25,8 & 4 & 6,4 & 42 & 67,8 & 64 & 100 \\
\hline Medias & 29 & 20,5 & 12 & 8,5 & 100 & 71 & 141 & 100 \\
\hline Chambras & - & - & - & - & 5 & 100 & 5 & 100 \\
\hline
\end{tabular}

FuENTE: AHPL (Inventarios bienes de 10 familias: total 23 inventarios).

El ropero femenino también mostrará la misma tendencia: basquiñas, almillas, camisas, justillos, zagalejos, mantillas, mandiles, cabriolés, camisas de mujer, enaguas, etc., fabricadas con fibras de peor calidad, como el lino, la estameña, pero también de otras más lujosas como las sedas del tafetán ${ }^{38}$.

Por lo tanto, todavía no se aprecian en los roperos ni masculinos ni femeninos la llegada de las nuevas prendas burguesas. Así, en las prendas masculinas solo a finales del siglo XviII aparecen los chalecos, elaborados algunos, no todos, con

36. El comerciante Miguel Fernández Chicarro tiene, según el inventario postomortem que se realiza en 1782, prendas de vestir donde figuran un frac con su chupa de paño valorado en 34 reales y cuatro jubones, donde sobresale uno de terciopelo tasado en 20 reales. Idem, Manuel Rico, caja 701.

37. Los calzoncillos de lienzo son muy frecuentes. Así, en el inventario de Miguel Fernández Chicarro hay un total de veinte y en el de José Casado Valcarce, realizado en 1797, dos de lienzo. Ibidem.

38. Sobresale entre la ropa femenina del inventario de Miguel Fernández Chicarro, un brial y media bata forrado en tafetán tasado en la elevada cantidad de 300 reales. Ibidem. 
la nueva fibra textil: el algodón ${ }^{39}$. Y en las femeninas harán acto de presencia las medias, bien de hilo o preferentemente de seda, con colores más llamativos: verdes; y los pañuelos de algodón encarnados ${ }^{40}$.

Las familias de comerciantes con residencia en las villas de la provincia, La Bañeza, Astorga, dispondrán de las mismas piezas de ropa ya analizadas con la particularidad de que sus roperos serán más pobres, tanto por el menor número de prendas existentes, como por la tipología y calidad de las mismas. Así, son más comunes los calzones, las chupas, las casacas y los capotes en el vestuario masculino y las almillas, basquiñas, manteos y enaguas en los femeninos. Las novedades serán también muy insignificantes, ya que solo se localizará un chaleco a finales del siglo XviII ${ }^{41}$.

Los primeros años del siglo xIx los podemos considerar como de transición, ya que son más abundantes los chalecos tanto en la ciudad como en las villas, y aparecen como novedades en las prendas masculinas las chaquetas, preferentemente de algodón $\mathrm{n}^{42}$, y en las femeninas las medias, sobre todo de seda, y los pañuelos de algodón, percal, con colores más llamativos: encarnados, verdes, etc. ${ }^{43}$.

A partir de los años veinte o mejor treinta del siglo xIX asistimos de forma clara a una transformación de los roperos de las familias comerciantes, con la mayor presencia en los mismos de las novedades burguesas, elaboradas de forma prioritaria con las nuevas fibras textiles: algodón ${ }^{44}$. Además, como es conocido, dichas innovaciones serán más visibles en la ciudad que en las villas leonesas ${ }^{45}$. De este modo, en el vestuario masculino las piezas antiguas conviven, pero teniendo cada vez menor relevancia, con las nuevas prendas de estilo más burgués. Así, en la ropa personal de los varones ya junto a las capas aparecerán los frac y las levitas ${ }^{46}$ y sobre todo los chalecos de seda, terciopelo y principalmente de algodón,

39. Entre las prendas de vestir inventariadas en el inventario de Miguel Fernández Chicarro hay cinco chalecos de niño, de algodón y lienzo, valorados en 10 reales. Ibidem.

40. En el inventario ya citado uno de 18 reales. Ibidem.

41. En el inventario de Nicolás San Martín, de la Bañeza, tasado en solo cuatro reales.

42. Como la que tiene José Pablos Salán, en 1812, valorada en 30 reales. Idem, Antonio Ginovés Martín, caja 1011.

43. Es lo que sucede en el inventario de Agustín Fernández Chicarro, en 1816, donde hay un pañuelo de percal encarnado valorado en 20 reales y otro pañuelo de algodón verde tasado en 10 reales. Id., Domingo Castañón Rodríguez, caja 906.

44. Tendencia ya apreciada, por Ramón Maruri Villanueva, entre la burguesía mercantil de Santander, a partir de los años treinta. Maruri VillanueVa, R.: «Vestir el cuerpo, vestir la casa. El consumo de textiles en la burguesía mercantil de Santander, 1700-1850», en Torras, J. y Yun, B. (dirs.): Consumo, condiciones de vida y comercialización. Cataluña y Castilla, siglos XVII-XIX. Ávila, 1999, p. 164

45. Ver trabajos de los grupos de investigación sobre consumo nacionales ya citados.

46. Presentes solo en el inventario del comerciante de origen catalán, Ramón Selva, en 1830, de paño generalmente negro o azul, con tasaciones elevadas: entre 36 y 90 reales para los fracs y entre 
los cuales tendrán cada vez más importancia, el 69\% del total localizados en la ciudad, predominando los colores ${ }^{47}$. Lo mismo sucederá con las chaquetas, el $91,7 \%$ de las mismas en la ciudad, de algodón (piqué, Mahón) ${ }^{48}$. Y finalmente, serán también más frecuentes los sombreros, los guantes y hará acto de presencia otra prenda masculina novedosa: el pantalón, elaborado con fibras tradicionales: la lana (paño), y sobre todo con el algodón: Mahón, predominado los colores oscuros (negro, gris).

La tendencia que hemos dibujado para la vestimenta masculina de las familias de comerciantes de la ciudad se observa también en el ropero femenino. Así, a partir de los años treinta del siglo xIx, las prendas más novedosas, de carácter burgués, se convierten en las de mayor demanda y son las que prevalecen frente a las tradicionales. Es lo que sucede con las medias y los pañuelos que están fabricados en fibras de calidad: cachemir, seda, y algodón ${ }^{49}$. Además, llegarán los relevantes vestidos de seda y sobre todo de algodón (sarasa), los cuales introducirán mayor colorido (verde) ${ }^{50}$ y las chambras de algodón, preferidas de nuevo por las familias de origen catalán ${ }^{51}$.

Las familias de comerciantes de las villas, Astorga, La Bañeza, seguirán las mismas tendencias en el consumo de las prendas de la vestimenta personal a partir de los años treinta del siglo XIX, adquiriendo las nuevas prendas de moda burguesas que ya lucían en la capital.

No obstante, el protagonismo a nivel social de las pautas de consumo, con la llegada de novedades, no corresponderán a las familias dedicadas al mundo de los negocios, sino que serán las familias de la burguesía administrativa y de profesiones liberales las que se adelantarán a las modas en la ropa personal. Así, en las piezas

42 y 80 reales para las levitas. Estas prendas novedosas también figuran a partir de estos años en la burguesía mercantil de Santander, constituyendo el frac una prenda refinada. La tendencia hacia los colores oscuros puede ser interpretada como metáfora de un cambio en las actitudes mentales de la burguesía, exigentes de una imagen de seriedad en los negocios. Maruri Villanueva, R.: «Vestir el cuerpo, vestir la casa...», p.164.

47. Resulta curioso los dos chalecos del anterior comerciante de seda y pelo de camello. AHPL, Ildefonso García Álvarez, caja 1167.

48. Destacando una "chaqueta de primavera», que posee Fernando Carrillo. Id., Ignacio Bayón Luengo, caja 1126. Para una mayor información sobre este tipo de telas ver Dávila Corona, R. M.a, Durán Pujol, M. y García Fernández, M.: Diccionario Histórico de Telas y Tejidos. CastellanoCatalán. Salamanca, 2004.

49. Algunos hacen referencia a «pañuelos de la India», como en el inventario ya citado anteriormente de Fernando Carrillo, cuya tasación tampoco es muy elevada: 70 reales. A AHPL, Ignacio Bayón Luengo, caja 1126.

50. Al igual que sucedía en las familias de comerciantes de Santander. Maruri Villannueva, R.: «Vestir el cuerpo, vestir la casa...», p. 165.

51. Del total de ocho chambras localizadas, cinco forman parte del ropero de Ramón Selva. AHPL, Ildefonso García Álvarez, caja 1167. 
del ropero masculino del siglo xviri, segunda mitad, ya harán acto de presencia los chalecos y también los guantes y los sombreros ${ }^{52}$. Y en los primeros años del siglo XIX, hasta 1824, al lado de los ya abundantes chalecos -de lienzo, etc., pero sobre todo de algodón (piqué, cotonia) - sobresalen las chaquetas y de forma más clara los pantalones, con un $47,8 \%$ del total de piezas inventariadas en la muestra analizada, elaborados todavía con las fibras tradicionales, de paño, y con las nuevas del algodón: Mahón ${ }^{53}$. Por lo tanto, no habrá que esperar a los años treinta del nuevo siglo, para que las familias de la burguesía de funcionarios y de profesiones liberales, de la capital leonesa, introduzcan el consumo de las prendas de moda burguesas en la vestimenta personal externa, exceptuando las más refinadas de los comerciantes de procedencia catalana. De ahí, que cuando las familias de negocios demandan con mayor intensidad dichas prendas, a partir de los años treinta, ya han sido asumidas por las otras familias ${ }^{54}$, con alta presencia en sus baúles más que armarios, que se emplazan en las alcobas y también en los gabinetes ${ }^{55}$.

Ahora bien, la dinámica vanguardista de consumo de los varones de las familias de la burguesía administrativa y de profesiones liberales en cuanto a las novedades en el vestir el cuerpo, no son tan perceptibles en las mujeres de las mismas familias, las cuales se encuadran más en los comportamientos ya analizados de las mujeres de negocios. De este modo, es cierto que las medias ya se adquieren para su ropero en el siglo XVIII, sobre todo en la segunda mitad, pero no será hasta los primeros años del siglo xix cuando tengan un mayor peso los pañuelos ${ }^{56}$, y habrá que esperar a los años treinta para que ya encontremos la prenda innovadora por excelencia: los vestidos, fabricados con la nueva fibra que permite la introducción de estampados y colores más vivos: el algodón (percal, sarasa, etc.) $)^{57}$.

52. Don Antonio Arana, administrador de la Real Gracia del Excusado, tiene dos chalecos de bombasí (tela de seda). Idem, Juan de Dios Fernández, caja 948.

53. En 1824 don Joaquín Álvarez Escaja posee once pantalones preferentemente de paño valorados en 442 reales. Idem, Felipe Morala Rodríguez, caja 1065.

54. Como ejemplo, en el inventario postmortem del arquitecto don Fernando Sánchez Pertejo, en 1840, abundan los chalecos, cinco de seda, y sobre todo los pantalones, un total de 18, de piqué, Mahón, etc., Id., Félix de las Vallinas, caja 1135.

55. Sorprende la escasa presencia de los armarios, tan importantes según D. Roche en el siglo xviII para el pueblo parisino, la abundancia de baúles para guardar la ropa, pero hay que tener en cuenta el carácter temporal de las estancias de estas familias debido a su profesión, lo que hacía que los baúles fuesen el mobiliario preferido. Lógicamente el armario permite colocar un mayor número de productos textiles y realizarlo de forma vertical, más de cara a la exposición y la vista, frente a la acumulación horizontal tradicional de las arcas y baúles. Roche, D.: Histoire des Choses Banals..., pp. 203-204.

56. Medias inglesas se inventarían en 1824, de color blanco, tasadas en 16 reales. Y en el mismo inventario hay 41 pañuelos, de algodón (percal), seda, etc., valorados en 299 reales. AHPL, Felipe Morala Rodríguez, caja 1065.

57. Sobresalen los 14 vestidos que figuran en el inventario de Fernando Sánchez Pertejo, en 1840, con una tasación muy alta: 2.040 reales. Id., Félix de las Vallinas, caja 1135. 
CuAdro 2. Las nuevas prendas en la vestimenta personal de la burguesía administrativa y profesiones liberales. Ciudad de León (1750-1850). (Piezas y porcentajes según el stock de bienes totales inventariados)

\begin{tabular}{|l|c|r|r|r|r|r|r|c|}
\hline & \multicolumn{2}{|c|}{$1750-1799$} & \multicolumn{2}{|c|}{$1800-1824$} & \multicolumn{2}{|c|}{$1825-1850$} & \multicolumn{2}{c|}{ TOTALES } \\
\hline PRENDAS MASCULINAS & \multicolumn{1}{|c|}{$\mathrm{N}^{\mathrm{o}}$} & \multicolumn{1}{c|}{$\%$} & \multicolumn{1}{c|}{$\mathrm{N}^{\circ}$} & \multicolumn{1}{c|}{$\%$} & \multicolumn{1}{c|}{$\mathrm{N}^{\circ}$} & \multicolumn{1}{c|}{$\%$} & \multicolumn{1}{c|}{$\mathrm{N}^{\circ}$} & $\%$ \\
\hline Chalecos & 4 & 4 & 67 & 68,5 & 27 & 27,5 & 98 & 100 \\
\hline Chaquetas & - & - & 3 & 75 & 1 & 25 & 4 & 100 \\
\hline Pantalones & - & - & 22 & 47,8 & 24 & 52,5 & 46 & 100 \\
\hline Sombreros & 7 & 53,8 & 4 & 30,7 & 2 & 15,5 & 13 & 100 \\
\hline Guantes & 7 & 21,8 & 15 & 46,9 & 10 & 31,3 & 32 & 100 \\
\hline PRENDAS FEMENINAS & & & & & & & & \\
\hline Vestidos & - & - & - & - & 18 & 100 & & 100 \\
\hline Pañuelos & 2 & 1,3 & 71 & 45,8 & 82 & 52,9 & 155 & 100 \\
\hline Medias & 40 & 26 & 86 & 55,4 & 28 & 18,6 & 154 & 100 \\
\hline Chambras & - & - & - & - & - & - & - & 100 \\
\hline
\end{tabular}

FueNte: AHPL (Inventarios bienes de 15 familias: total 20 inventarios).

En las villas, Ponferrada, la demanda de las novedades será mucho más tardía y ralentizada, al igual que veíamos con las familias de comerciantes, tanto en los varones como en las mujeres. Así, todavía en los años veinte del sigo XIX seguirán predominando las piezas tradicionales y solo encontraremos $\operatorname{chalecos}^{58} \mathrm{y}$ sombreros ${ }^{59}$.

En definitiva, la profesión y el lugar de residencia son factores muy importantes a la hora de analizar la demanda de nuevas prendas de la vestimenta personal. Factores, por otro lado, que ya fueron señalados por los estudios realizados sobre el consumo ${ }^{60}$. No obstante, si que consideramos de especial relevancia el hecho de que sean las familias de funcionarios y profesionales liberales las más vanguardistas en comparación con las dedicadas al mundo de los negocios, y que las protagonistas, contra lo que pudiera pensarse a priori, no fueran las mujeres sino los varones.

58. Su número tampoco será muy elevado, por ejemplo en el inventario de don José de Gayo y García, administrador principal que fue de la hacienda pública de Ponferrada y su partido, solo encontramos tres chalecos, uno de ellos elástico de algodón valorado en 10 reales.

59. Uno apuntado tasado en 30 reales en el inventario de don Manuel Sánchez Romero, en 1825, contador de todas las rentas reales de la villa de Ponferrada.

60. Ver los trabajos de los grupos de investigación ya citados. 
Profundizando en este estudio, nos planteamos si este análisis más cualitativo, del consumo familiar de las prendas del ropero personal, se corresponde con una mayor inversión de dinero. De acuerdo con análisis ya realizados ${ }^{61}$, conocemos que la ropa personal inventariada de las familias de la burguesía de negocios de la ciudad leonesa representa entre el 11,1\%, de los comerciantes-financieros, y el $13 \%$ de los comerciantes, total de bienes que conforman lo que denominamos las condiciones y estilo de vida ${ }^{62}$. Y en las familias de la burguesía administrativa el $12,7 \%$ y el más elevado del $18,7 \%$ en las de profesiones liberales. En general, exceptuando los miembros de las profesiones liberales el resto de las familias se mantienen en unos niveles de valoración de sus roperos muy similares.

CUADRo 3. Valoración ropa personal familias burguesía. 1700-1850 (Medias reales)

\begin{tabular}{|l|c|c|c|c|}
\hline & \multicolumn{2}{|c|}{ BURGUESÍA NEGOCIOS } & \multicolumn{2}{c|}{ BURGUESÍA ADMI. Y PROF. LIBERALES } \\
\hline & CIUDAD & VILLAS & CIUDAD & VILLAS \\
\hline Siglo XVIII & 3.260 & 1.080 & 1.747 & - \\
\hline $1800-1824$ & 2.046 & - & 5.127 & 631 \\
\hline $1825-1849$ & 3.144 & 2.176 & 5.287 & 540 \\
\hline
\end{tabular}

FuENTE: A.H.P.L. (Inventarios de bienes de 36 familias: total 54 inventarios).

Sin embargo, donde se aprecian más contrastes es en las medias de tasación de las piezas de vestimenta personal y sus dinámicas evolutivas. Así, las familias de los negocios tendrán las medias más altas, 3.260 reales, en la segunda mitad del siglo XVIII, descendiendo a 2.046 reales en 1800-1824 y volviendo a recuperar casi los valores de partida en los años 1825-1849, con 3.144 reales. En cambio, las familias de los funcionarios y profesiones liberales partirán de medias de valoración mucho más bajas, tan solo 1.747 reales en la segunda mitad del siglo xviII, pero en la primera mitad del siglo xIX alcanzarán cantidades superiores a los 5.000 reales: 5.127 reales en $1800-1824$ y 5.287 reales en $1825-1849$. Por lo tanto, hay una mayor inclinación en las últimas familias descritas a la hora de tener vestuarios personales de mayor valor a comienzos y hasta mediados del siglo XIX.

61. Bartolomé Bartolomé, J. M.: «Niveles de riqueza patrimonial, condiciones de vida y pautas de consumo de las familias de comerciantes y financieros de la ciudad de León (1750-1850), en Revista Nuevo Mundo. Mundos Nuevos, revista electrónica de L'Ecole des Hautes Etudes en Sciences Sociales, N. ${ }^{\circ}$. «Patrimonios, condiciones de vida y consumo. La burguesía administrativa y las profesiones liberales en la ciudad de León, 1700-1850», en García Fernández, M. (dir.): Cultura material y vida cotidiana..., pp. 73-91.

62. Agrupadas en los siguientes apartados: Decoración de la casa (objetos religiosos), mobiliario de la casa, útiles de cocina (menaje loza fina), ropa personal, ropa cama, ropa casa, joyas y alhajas, libros. 
Ahora bien, ¿qué peso tienen las nuevas prendas masculinas y femeninas? En la burguesía comercial y financiera las novedades solo significarán una cantidad significativa en el periodo de $1825-1849$, con un $20,2 \%$, ya que en los periodos anteriores solo se situará entre el 7,6\% y el 6,3\%. En cambio, en las familias de funcionarios y profesionales liberales ya desde comienzos del siglo xIX representarán el 26\% de la valoración total, llegando a alcanzar el 31,1\% en 1825-1849.

Cuadro 4. Valoración de las novedades en la ropa personal en las familias de la burguesía. Ciudad de León. 1700-1850 (Medias reales)

\begin{tabular}{|l|c|c|c|c|}
\hline & \multicolumn{2}{|c|}{ BURGUESÍA NEGOCIOS } & \multicolumn{2}{c|}{ BURGUESÍA ADMI. Y PROF. LIBERALES } \\
\hline & Ropa masculina & Ropa femenina & Ropa masculina & Ropa femenina \\
\hline Siglo xviII & 75 & 173 & 15 & 27 \\
\hline $1800-1824$ & 32 & 98 & 724 & 607 \\
\hline $1825-1849$ & 157 & 478 & 106 & 1.538 \\
\hline
\end{tabular}

Fuente: A.H.P.L. (Inventarios de bienes de 25 familias: total 43 inventarios).

En definitiva, la burguesía profesional no solo tendrá roperos personales de mayor valoración, sino que también desde el siglo XIX se decantará más por la inversión en prendas de la nueva moda burguesa tanto masculina como especialmente femenina. Este predomino de las piezas femeninas se aprecia de forma clara en las valoraciones de toda la muestra y de todas las familias, pero sobre todo en las familias de la burguesía profesional en el periodo de 1825-1849, donde la ropa nueva femenina es valorada en una media de 1.538 reales y en cambio la masculina tan solo en una media de 106 reales $^{63}$.

\section{LOS OBJETOS DE ADORNO PERSONAL: JOYAS Y ALHAJAS}

Como complemento de la vestimenta externa, y además como muestra de solvencia económica, no hay que olvidar la importancia que tenían las joyas y alhajas de uso personal destinadas a aparentar en sociedad. Además de adornar mostraban una figura sobria en su vestimenta pero elegantemente adornada,

63. Así, sobresale el ejemplo del arquitecto don Fernando Sánchez Pertejo, el cual tiene un patrimonio familiar, en 1840 , valorado, una vez descontadas las deudas, en 580.841 reales. La ropa personal adquiere una tasación de 9.720 reales, superior a la ropa de cama y casa y al mobiliario de casa. Las novedades en el vestuario significan el $35,5 \%$ de su valoración, con 3.450 reales, y de ellos tan solo 133 reales son de prendas masculinas. De ahí, que predominen los vestidos, en total 16, valorados en 2.180 reales, las medias de seda, un total de 20 , y los pañuelos, un total de 28. A.H.P.L., Félix de las Vallinas, Caja 1135. 
demostrando a parte de un cierto lujo en cuanto a la apariencia personal una capacidad económica ${ }^{64}$

En los estudios de las condiciones y estilo de vida observábamos la relevancia que tenían en general las piezas de oro y plata, bien de cubertería de la casa o personales, situándose en porcentajes de valoración, en los inventarios postmortem, que iban desde los más altos del 43,3\% de la burguesía administrativa a los más inferiores del 22,9\% de las familias de profesiones liberales, pasando por el $36,6 \%$ de los comerciantes ${ }^{65}$. En definitiva, cantidades que nos hablaban del fuerte peso de dichos objetos de valor, lo cual no era nada novedoso en el caso de las familias centradas en los negocios comerciales o financiero, debido a la obligatoriedad de poder asegurar y dar prestigio a sus actividades económicas más arriesgadas ${ }^{66}$.

No obstante, consideramos que este estudio encubre una mayor complejidad, siendo necesario reconstruir las dinámicas de consumo de las diferentes familias burguesas y su trayectoria a lo largo de los años. De este modo, en una primera aproximación cuantitativa, apreciamos cómo las valoraciones globales de los objetos y alhajas de oro y plata son más elevadas en las familias de funcionarios y de profesiones liberales que en las de la negociantes ${ }^{67}$. Así, las medias de los comerciantes y financieros estarán entre 5.512 reales en el siglo xviII y 9.580 reales en 1800-1824, pasando a 6.340 reales en 1825-1849. En cambio las de los miembros de las otras profesiones será la más baja en el periodo 1825-1849 con 2.670 reales, pero la del siglo XVIII será de 10.455 reales y la de 1800-1824 alcanzará los 15.013 reales.

Cuadro 5. Valoración piezas de oro y plata familias burguesía. 1700- 1850 (Medias reales)

\begin{tabular}{|l|c|c|c|c|c|c|c|c|}
\hline & \multicolumn{3}{|c|}{ BURGUESÍA NEGOCIOS } & \multicolumn{2}{c|}{ BURGUESÍA ADMI. Y PROF. LIBERALES } \\
\hline & \multicolumn{2}{|c|}{ CIUDAD } & \multicolumn{2}{c|}{ VILLAS } & \multicolumn{2}{c|}{ CIUDAD } & \multicolumn{2}{c|}{ VILLAS } \\
\hline & Cubertería & Joyas & Cubertería & Joyas & Cubertería & Joyas & Cubertería & Joyas \\
\hline S. xVIII & 3.186 & 2.326 & 531 & 74 & 7.802 & 2.653 & - & - \\
\hline $1800 / 1824$ & 7.378 & 2.202 & - & - & 13.753 & 1.260 & 621 & 14 \\
\hline $1825 / 1849$ & 3.339 & 3.001 & 1.734 & 2.492 & 2.249 & 421 & 922 & 150 \\
\hline
\end{tabular}

FuENTE: AHPL(Inventarios de bienes de 36 familias: total 54 inventarios).

64. Dávila Corona, R. M.à: «Los patrimonios de la burguesía comercial vallisoletana, 17601860», en Cultura material y vida cotidiana..., p. 106.

65. También constituyen un capítulo de gran importancia dentro del ajuar de las familias de comerciantes de Valladolid, llegando a suponer entre el 20 y el $26 \%$ del ajuar. En cambio en la burguesía intelectual los objetos de oro y plata solo suponen entre el 15\% y el 30\%, teniendo más peso los libros. Idem, pp. 106-107.

66. Ver Angulo Morales, A.: Del éxito en los negocios..., p. 318.

67. Al contrario de lo que sucedía en ciudad vallisoletana. DÁvila Corona, R. M.a: «Los patrimonios de la burguesía comercial ...», en Cultura material y vida cotidiana..., pp. 106-107. 
Por lo tanto, mayores niveles patrimoniales no se corresponden con la posesión de objetos de oro y plata de mayor valoración, aunque sean tan imprescindibles para el futuro y buen devenir de sus empresas comerciales y financieras. Al contrario, serán las familias con menos patrimonios pero más refinadas en sus gustos las que se impongan en este tipo de piezas de valor.

Ahora bien, dentro de la apreciación global anteriormente descrita se encubren dinámicas distintas e interesantes si nos centramos en la diferente tipología de las piezas de consumo de oro, plata, etc. De este modo, frente a la fuerte hegemonía de las piezas de cubertería de la casa en la burguesía administrativa y de profesiones liberales a lo largo del siglo xviII y en la primera mitad del siglo xIX -donde en el periodo $1800-1824$ su tasación será del $91,6 \%$ y en $1825-49$ el $84 \%-$, en las otras familias de negociantes los objetos de oro y plata de uso personal mantendrán un mayor peso tanto en el siglo xviII, segunda mitad, con un $42,2 \%$ del global de la tasación, pasando al 47,4\% a partir del periodo 1825-1849. En definitiva, en la primera mitad del siglo xix, y sobre todo a partir de los años 30 , son las familias de comerciantes y financieros las que muestran mayor inclinación por el consumo de joyas y alhajas de uso personal, en la línea ya apreciada de las prendas de ropa destinadas a vestir el cuerpo ${ }^{68}$.

Las villas leonesas, Ponferrada, Astorga, La Bañeza, siguen las pautas anteriormente descritas para la ciudad, destacando como en las familias de negocios, la valoración de las joyas personales incluso supera en 1825-1849 a las piezas de cubertería de uso doméstico: $59 \%$ frente a $41 \%$ respectivamente.

Si pasamos a un análisis más cualitativo todavía serán más las sorpresas, produciéndose un cambio significativo en las joyas y alhajas personales de las familias de negocios a partir del siglo xIX, sobre todo años treinta, donde la temática tradicional religiosa deja paso a la profana. Así, en la ciudad en el siglo xviII son más abundantes los relicarios y los escapularios, con el $100 \%$ de las piezas del total de la muestra, las cruces, con el $75 \%$ y los rosarios con el $44,4 \%{ }^{69}$. En cambio, en el período de $1825-1849$ sobresalen los anillos y sortijas, con un $64 \%$ del total de las piezas de la muestra, los pendientes (zarcillos), con un $60 \%$, las cadenas con un $77 \%$, los relojes de bolsillo con un $66,7 \%$ y finalmente los alfileres para las corbatas, con el $100 \%{ }^{70}$.

68. En la ciudad de Valladolid ocurre de nuevo lo contrario, ya que los comerciantes se inclinarán más a partir de la primera mitad del siglo XIX, sobre todo a partir de la década de 1820 , por los objetos de cubertería, suponiendo en muchos casos más de la mitad del valor. Idem, pp. 106-107.

69. En el inventario de Miguel Fernández Chicarro, en 1782, hay tres rosarios valorados en 85 reales, tres cruces tasadas en 94 reales y dos escapularios en 12 reales. AHPL, Manuel Rico, caja 701. Y José Casado Valcarce, tendrá también tres relicarios, valorados en 36 reales.

70. El comerciante con piezas de oro y plata de uso personal de mayor valoración es José Fernández Chicarro, en 1848, con 6.409 reales, el cual tiene dos relojes de bolsillo tasados en 250 reales, 
CUADRo 6. Los cambios en las alhajas y joyas personales de la burguesía comercial y financiera. Ciudad de León (1750-1850). (Piezas y porcentajes según el stock de bienes totales inventariados)

\begin{tabular}{|c|c|c|c|c|c|c|c|c|}
\hline & \multicolumn{2}{|c|}{$1750-1799$} & \multicolumn{2}{|c|}{$1800-1824$} & \multicolumn{2}{|c|}{$1825-1850$} & \multicolumn{2}{|c|}{ TOTALES } \\
\hline PIEZAS & $\mathrm{N}^{\mathrm{o}}$ & $\%$ & $\mathrm{~N}^{\mathrm{o}}$ & $\%$ & $\mathrm{~N}^{\mathrm{o}}$ & $\%$ & $\mathrm{~N}^{\circ}$ & $\%$ \\
\hline Relicarios & 3 & 100 & - & - & - & - & 3 & 100 \\
\hline Cruces & 6 & 75 & 1 & 12,5 & 1 & 12,5 & 8 & 100 \\
\hline Rosarios & 4 & 44,4 & 1 & 11,2 & 4 & 44,4 & 9 & 100 \\
\hline Escapularios & 1 & 100 & - & - & - & - & 1 & 100 \\
\hline Anillos-sortijas & 7 & 28 & 2 & 8 & 16 & 64 & 25 & 100 \\
\hline Collares & 4 & 57,1 & 1 & 14,3 & 2 & 28,6 & 7 & 100 \\
\hline Pulseras & 1 & 100 & - & - & - & - & 1 & 100 \\
\hline Pendientes & 7 & 35 & 1 & 5 & 12 & 60 & 20 & 100 \\
\hline Espadín y bastón & 3 & 75 & 1 & 25 & - & - & 4 & 100 \\
\hline Aderezos & 2 & 100 & - & - & - & - & 2 & 100 \\
\hline Hebillas & - & - & - & - & 1 & 100 & 1 & 100 \\
\hline Cadenas & - & - & 3 & 23 & 10 & 77 & 13 & 100 \\
\hline Relojes & - & - & 2 & 33,3 & 4 & 66,7 & 6 & 100 \\
\hline Botones & 4 & 100 & - & - & - & - & 4 & 100 \\
\hline Alfileres & - & - & - & - & 2 & 100 & 2 & 100 \\
\hline
\end{tabular}

FuENTE: AHPL (Inventarios bienes 10 familias: total 23 inventarios).

La trayectoria apreciada en las villas, Astorga, La Bañeza, es muy similar, pero con la particularidad de que todavía en los años 1825-1840 siguen teniendo una presencia más significativa los relicarios y las cruces personales con un $71,4 \%$ del total de las piezas de la muestra y los rosarios con un $80 \%$.

Del mismo modo, las familias de funcionarios y profesiones liberales de la ciudad también se inclinarán por la adquisición y compra de las nuevas joyas de temática más profana, pero la diferencia con las anteriores es que lo harán antes, segunda mitad del siglo XviII, de tal forma que en el periodo de 1825-1840, el de mayor intensidad de las familias de negocios, la posesión de dichas alhajas

dos cadenas en 1.679, tres pendientes en 610 reales, dos aros en 120 reales, y una piedra guarnecida de esmeralda en 3.000 reales. No obstante, donde ya se aprecia un claro predominio de estas alhajas de temática más profana es en las familias de origen catalán, como en Ramón Selva, en 1830, donde solo encontramos un rosario con medallas de plata valorado en 12 reales, frente a los anillos, sortijas, cadenas, pendientes, zarcillos, collares, relojes de bolsillo, etc., valorados todos en 1.186 reales. Idem, Felipe Morala Rodríguez, caja 1070 e Ildefonso García Álvarez, caja 1167. 
será menos intensa. Es, por lo tanto, un proceso similar al observado para la ropa personal. De este modo, ya en los años setenta del siglo XviII, al lado de los relicarios, cruces, rosarios y escapularios, aparecerán anillos y sortijas, con un $61,1 \%$ del total de piezas de la muestra, collares con un $625 \%$, pulseras con un $50 \%$, pendientes con un $28,6 \%$, hebillas de corbatín con un $62 \%$ y relojes de bolsillo con un $42,8 \%{ }^{71}$. Y a partir de los años treinta del siglo xIx desaparecerán definitivamente todas las joyas de temática religiosa ${ }^{72}$.

Cuadro 7: Los cambios en las alhajas y joyas personales de la burguesía administrativa y profesiones liberales. Ciudad de León (1750-1850). (Piezas y porcentajes según el stock de bienes totales inventariados)

\begin{tabular}{|c|c|c|c|c|c|c|c|c|}
\hline & \multicolumn{2}{|c|}{$1750-1799$} & \multicolumn{2}{|c|}{$1800-1824$} & \multicolumn{2}{|c|}{$1825-1850$} & \multicolumn{2}{|c|}{ TOTALES } \\
\hline PIEZAS & $\mathrm{N}^{\circ}$ & $\%$ & $\mathrm{~N}^{\mathrm{o}}$ & $\%$ & $\mathrm{~N}^{\mathrm{o}}$ & $\%$ & $\mathrm{~N}^{\mathrm{o}}$ & $\%$ \\
\hline Relicarios & 21 & 91,3 & 2 & 8,7 & - & - & 23 & 100 \\
\hline Cruces & 8 & 80 & 2 & 20 & - & - & 10 & 100 \\
\hline Rosarios & 3 & 100 & - & - & - & - & 3 & 100 \\
\hline Escapularios & 1 & 100 & - & - & - & - & 1 & 100 \\
\hline Anillos-sortijas & 11 & 61,5 & 5 & 27,8 & 2 & 11,1 & 18 & 100 \\
\hline Collares & 5 & 62,5 & 1 & 12,5 & 2 & 25 & 8 & 100 \\
\hline Pulseras & 4 & 50 & 2 & 25 & 2 & 25 & 8 & 100 \\
\hline Pendientes & 2 & 28,6 & - & - & 5 & 71,4 & 7 & 100 \\
\hline Espadín y bastón & 6 & 50 & 2 & 16,6 & 4 & 33,3 & 12 & 100 \\
\hline Aderezos & 6 & 100 & - & - & - & - & 6 & 100 \\
\hline Hebillas (corbatín) & 18 & 62 & 11 & 38 & - & - & 29 & 100 \\
\hline Cadenas & - & - & 3 & 100 & - & - & 3 & 100 \\
\hline Relojes & 3 & 42,8 & - & - & 4 & 57,2 & 7 & 100 \\
\hline Medallas & - & - & 4 & 50 & 4 & 50 & 8 & 100 \\
\hline Alfileres & - & - & 1 & 100 & - & - & 1 & 100 \\
\hline
\end{tabular}

FuENTE: AHPL (Inventarios bienes de 15 familias: total 20 inventarios).

71. Don Manuel García de Brizuela, abogado de los Reales Consejos, cuyo inventario se realiza en 1777, es el mejor ejemplo, ya que poseerá once relicarios, uno de oro tasado en 240 reales, medallas religiosas, cruces de Caravaca, pero también collares de perlas, uno de ellos valorado en 1.620 reales, anillos de oro, anillos con zafiro, etc. Idem, Pedro Hevia Lorenzana, caja 749.

72. Así, en don Fernando Sánchez Pertejo solo encontraremos dos espadines de puño de oro y tres relojes de bolsillo, uno de ellos de plata tasado en 200 reales. Y en don Julián López, también un bastón de caña de puño de oro y collares, pulseras, sortijas, pendientes y un reloj de oro valorado en otros 200 reales. Idem, Félix de las Vallinas, caja 1135. 
En definitiva, se constata un consumo vicario de las familias de negocios de los comportamientos en la forma de vestir y adornar el cuerpo de las convecinas dedicadas al mundo profesional, bien funcionarios o profesiones liberales, ya que son estas últimas las que primero adquieren y exponen en público las nuevas prendas textiles de la moda burguesa y las joyas y alhajas más innovadoras. Sin embargo, las familias de comerciantes y financieros adoptarán de nuevo con mayor avidez las novedades.

\section{Conclusiones}

Existen importantes diferencias entre los niveles patrimoniales de las familias de la burguesía leonesa, siendo los más elevados los de las familias de la burguesía dedicadas al mundo del comercio y el comercio y las finanzas que reside en la capital, entre una media de 463.890 y 893.883 reales de bienes líquidos. En cambio, las familias de los funcionaros y profesiones liberales se sitúan entre 216.669 reales y 116.489 reales.

No obstante, la mayor o menor riqueza no implica en general una mayor cantidad destinada al consumo de bienes, que se pueden considerar más superfluos y conectados con las apariencias externas personales. Esto se aprecia muy bien en las valoraciones que tienen las prendas de la vestimenta personal, ya que las medias más elevadas no serán las de las familias de los negocios, sino las de profesiones liberales y al servicio de la administración, llegando casi a duplicarlas a partir de los años treinta del siglo xix: 3.144 reales frente a 5.287 reales. Además, también tendrán mayor peso las prendas de moda, tanto masculinas como femeninas, reafirmando la mayor tendencia al consumo de las novedades por parte de dichas familias, las cuales a su vez serán las pioneras en su demanda. Las demás seguirán su estela, consumo vicario, con retraso, pero mostrando mayor interés a partir del periodo 1825-1849, cuando pierde fuerza en las pioneras.

Las piezas de oro y plata, bien de cubertería o de uso personal, también ofrecerán unas valoraciones más altas en las familias de la burguesía administrativa y profesionales liberales, lo cual sorprende dada la gran importancia que tenía de cara al prestigio y solvencia de los negocios, la posesión de objetos en metales preciosos. No obstante, serán las familias de comerciantes y financieros las que demanden más los complementos destinados a la decoración del cuerpo, es decir, joyas y alhajas personales. Tendencia que se marcará con mayor claridad desde el siglo XIX y sobre todo a partir de los años treinta. Del mismo modo, serán las primeras familias las que imiten el consumo de piezas de complemento con temática profana, frente a la predominante religiosa de los años anteriores, que ya habían introducido las familias de funcionarios y de la administración, intensificando su 
consumo en el periodo 1825-1849, cuando ya se había ralentizado en las familias vanguardistas de las profesiones y administración.

En definitiva, pautas de consumo de familias burguesas que ofrece importantes novedades a la hora del estudio de los contrastes entre las familias, de acuerdo con el género, la residencia y sobre todo con la profesión, más que con el nivel económico o patrimonial.

\section{BibliografíA}

Angulo Morales, A.: Del éxito en los negocios al fracaso del consulado: la formación de la burguesía mercantil en Vitoria (1670-1840). Bilbao, 2000.

Azcona Guerra, A. M.a: Comercio y comerciantes en la Navarra del siglo XVIII. Pamplona, 1996.

Bartolomé Bartolomé, J. M.: Vino y viticultores en El Bierzo. Sociedad y estructuras económicas durante el siglo XVIII. León, 1996.

Bartolomé BARtolomé, J. M.: La hegemonía de una nueva burguesía en El Bierzo (1800-1850). León, 2000.

BARtolomé Bartolomé, J. M.: El tránsito al crecimiento económico moderno en León. Condiciones de vida y pautas de consumo en La Bañeza y Astorga. León, 2004

Bartolomé Bartolomé, J. M.: Familias de comerciantes y financieros en la ciudad de León (1700-1850). León, 2009.

Bartolomé Bartolomé. J. M. y García Fernández, M. (dirs.): Apariencias contrastadas: Contraste de Apariencias. Cultura material y consumos de Antiguo Régimen. León, 2012.

Barreiro Ballón, B.: «Las clases urbanas de Santiago en el siglo XviII: definición de un estilo de vida y de pensamiento» en La historia Social de Galicia en sus fuentes de protocolos. Santiago de Compostela, 1980, pp. 449-564.

DÁvila Corona, R. M.: «La cultura doméstica del profesorado vallisoletano en la segunda mitad del siglo XIX», en Las Universidades Hispánicas. De la monarquía de los Austrias al centralismo liberal. Salamanca, 2000, pp. 127-138.

DÁvila Corona, R. M.: «Los patrimonios de la burguesía comercial vallisoletana, 17601860», en Cultura material y vida cotidiana moderna: escenarios. Madrid, 2013, pp. 91-112.

Dávila Corona, R. M. a, Durán Pujol, M. y García Fernández, M.: Diccionario Histórico de Telas y Tejidos. Castellano-Catalán. Salamanca, 2004.

Dos Guimaraes Sá, I. y García Fernández, M. (dirs.): Portas Adentro, comer, vestir, habitar (ss. XVI-XIX). Coimbra, Valladolid, 2010.

Eiras Roel, A.: «Tipología documental de los protocolos gallegos», en La Historia social de Galicia en sus fuentes de protocolos, Santiago de Compostela, 1980, pp. 21-113.

Eiras Roel, A.: «La burguesía mercantil compostelana a medidos del siglo xvirI: mentalidad tradicional e inmovilismo económico», en La Historia social de Galicia en sus fuentes de protocolos, Santiago de Compostela, 1980, pp. 521-624. 
García Fernández, M.: (dir.), Cultura material y vida cotidiana moderna: escenarios. Madrid, 2013.

Franch Benavent, R.: El capital comercial valenciano en el siglo XVIII. Valencia, 1989.

García Baquero. A.: Cádiz y el Atlántico (1717-1778). Sevilla, 1976.

Gómez Carrasco, C. J.: Familia y capital comercial en la Castilla meridional. La comunidad mercantil en Albacete (1700-1835). Madrid, 2009.

Madureira, N. L.: Cidade: Espaço e Quotidian. Lisboa, 1992.

Marcos Martín, A.: «Historia y desarrollo: el mito historiográfico de la burguesía», en La Burguesía Española en la Edad Moderna. Valladolid, 1996, pp. 15-35.

Maruri Villanueva, R.: «Vestir el cuerpo, vestir la casa. El consumo de textiles en la burguesía mercantil de Santander, 1700-1850», en Torras, J. y Yun, B. (dirs.): Consumo, condiciones de vida y comercialización. Cataluña y Castilla, siglos XVII-XIX. Ávila, 1999, pp. 159-182.

Melón Jiménez, M. A.: Los orígenes del capital comercial y financiero en Extremadura. Compañias de comercios, comerciantes y banqueros de Cáceres (1773-1836). Badajoz, 1992.

Molas Ribalta, P.: La Burguesía mercantil en la España del Antiguo Régimen. Salamanca, 1985.

Pérez García, J. M.: Un modelo social leonés en crecimiento. La Vega Baja del Esla entre 1700-1850. León, 1989.

Roche, D.: La Culture des apparences. Une historie du vetemement, XVII-XVIII siècles. París, 1989.

Roche, D.: Historire des choses banales. Naissance de la consommation XVII-XIX siècle. París, 1997.

Rubio Pérez, L.: León, 1751. Según las Respuestas Generales del Catastro de Ensenada. Madrid, 1993.

Rubio Pérez, L.: La Bañeza y su tierra, 1650-1850, León, 1987.

Rubio Pérez, L.: Astorga. Un enclave señorial en los siglos XVII y XVIII. León, 1990.

Rubio Pérez, L.: La Burguesía maragata. Dimensión social, comercio y capital en la corona de Castilla durante la Edad Moderna. León, 1995.

Torres SÁnchez, R: «El hogar del burgués», en La Burguesía Española en la Edad Moderna, tomo I. Valladolid, 1996, pp. 253-268.

Yun Casalilla, B., Prólogo de Comprar, vender y consumir. Nuevas aportaciones a la historia del consumo en la España moderna. Muñoz Navarro, D. (ed.): Valencia, 2011, pp. 9-14. 